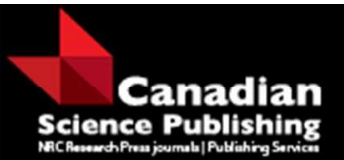

Canadian Journal of Forest Research

Revue canadienne de recherche forestière

\title{
Recovery Trends and Predictions of Fraser Fir (Abies fraseri) Dynamics in the Southern Appalachian Mountains
}

\begin{tabular}{|r|l|}
\hline Journal: & Canadian Journal of Forest Research \\
\hline Manuscript ID & cjfr-2016-0067.R1 \\
\hline Manuscript Type: & Article \\
\hline Date Submitted by the Author: & $29-$ Sep-2016 \\
\hline Keyword: List of Authors: & $\begin{array}{l}\text { Kaylor, S; University of Tennessee, Forestry, Wildlife and Fisheries } \\
\text { Hughes, M. Joseph; University of Tennessee, Ecology and Evolutionary } \\
\text { Biology } \\
\text { Franklin, Jennifer; University of Tennessee }\end{array}$ \\
\hline & $\begin{array}{l}\text { Bayesian hierarchical modeling, balsam woolly adelgid, Abies fraseri, cloud } \\
\text { forest, stage-structured matrix model }\end{array}$ \\
\hline
\end{tabular}

SCHOLARONEm

Manuscripts 


\section{Recovery Trends and Predictions of Fraser Fir (Abies fraseri) Dynamics in the Southern Appalachian Mountains}

4 S. Douglas Kaylor, M. Joseph Hughes \& Jennifer A. Franklin

$5 \quad$ Kaylor, S.D. (Corresponding author, doug.kaylor@gmail.com) ${ }^{1}$

6 Hughes, M.J. (m.joseph.hughes@gmail.com) ${ }^{2}$

$7 \quad$ Franklin, J.A. (jafranklin@utk.edu) ${ }^{1}$

$9 \quad{ }^{1}$ Forestry, Wildlife and Fisheries Department, University of Tennessee Knoxville, 2431 Joe 10 Johnson Drive, Knoxville, TN, USA;

$11{ }^{2}$ Department of Ecology and Evolutionary Biology, University of Tennessee Knoxville, 569

12 Dabney Hall, Knoxville, TN, USA 


\section{Abstract}

The endemic Fraser fir (Abies fraseri) is only found in seven montane regions in the southern Appalachians above ca. 1,500 m elevation. Due to widespread insect-caused mortality from the invasive balsam woolly adelgid (Adelges piceae) as well as possible impacts from climate change and atmospheric pollution, the future of Fraser fir populations remains uncertain. Long-term monitoring programs have been in place since the 1980's, and here we present the first predictive population models for endemic Fraser fir populations using the inventory data from Great Smoky Mountains National Park, which contains $74 \%$ of extant Fraser fir forests. Using two kinds of population data (understory density counts and overstory census data) we model Fraser fir population dynamics on five different mountaintops as a stage-structured matrix model with transition parameters estimated using hierarchical Bayesian inference. We predict robust recovery over the next several decades for some Fraser fir populations, particularly where mature overstory fir has persisted throughout the last two decades, and continued decline for populations at the lowest elevations. Fraser fir densities are already low at these lower elevations, suggesting this population is vulnerable to local extirpation.

Keywords: Bayesian hierarchical modeling, stage-structured matrix model, balsam woolly adelgid, Abies fraseri, 
32

33

34

35

36

37

38

39

40

41

42

43

44

45

46

47

48

49

51

52

53

54

55

56

\section{Introduction}

The southern Appalachian spruce-fir forest is a relict ecosystem found in only seven mountain-top populations ranging from Mt. Rogers in southwestern Virginia to the Great Smoky Mountains of eastern Tennessee and western North Carolina (Whittaker 1956). Currently occupying only about $26 \mathrm{kha}$ (Smith \& Nicholas 2000), the red spruce (Picea rubens)-Fraser fir (Abies fraseri) forests of the Southern Appalachians are currently listed as one of the most endangered ecosystems in the United States (Christensen et al. 1996). These forests are noted for their relatively high level of endemic species, especially within the pure fir stands found on the highest peaks (White 1984).

The current geographic distribution of Fraser fir covers about half of what it once did in the late nineteenth century (Dull et al. 1988). Logging and failed regeneration caused by site degradation dramatically reduced the range of Southern Appalachian spruce- fir in the early 1900s (Pyle \& Schafale 1988). Since the late 1950s, Fraser fir has experienced 67\% mortality of adult trees throughout the species' range, with up to $91 \%$ mortality in some areas of Great Smoky Mountains National Park (Dull et al. 1988). Impacts potentially contributing to this 47 decline are numerous. One well-known factor is depredation from the invasive insect Adelges

48 piceae, the balsam woolly adelgid (BWA). The insect feeds on the phloem of adult Fraser fir and 49 causes reduction in water and sap conductance, which generally results in tree mortality within 50 2-5 years (Hollingsworth \& Hain 1991). Additionally, acidic deposition associated with air 51 pollution is high in the montane cloud forests of the southern Appalachians (Nodvin et al. 1995), 52 and has been linked to increased foliar injury and early senescence, reduction in leaf chlorophyll 53 content, decreased cold hardiness, and alterations in soil aluminum and nutrient availability

54 (Borer et al. 2005; Jacobson et al. 1990; McLaughlin et al. 1990). Alterations to carbon balance 55 and foliar respiration associated with changing climate are another possible reason for reduced 56 forest health, as suggested by Tjoelker et al. 1999 in work on northern boreal tree species.

5 In the face of these changes, the future of Fraser fir populations remains uncertain. The

58 US Forest Service's 1988 regional assessment of spruce fir forests using aerial photography was

59 the last systematic inventory to document the total extent of high elevation forests in the southern 0 Appalachians, but is limited to presence/absence data for this forest type at a single point in time.

61 Several descriptive studies were done prior to the arrival of BWA (Oosting \& Billings 1951; 
62 Whittaker 1956), and other studies document changes occurring during the infestation's initial

63 outbreak (Busing et al. 1993; Busing et al. 1988; Dull et al. 1988).

64 Long-term monitoring programs were established during the 1980's throughout the range

65 of Fraser fir. A number of studies have detailed forest dynamics over the past few decades at

66 these sites (Jenkins 2003; Lusk et al. 2010; Mancusi 2004; McManamay et al. 2011; Moore et al.

67 2008), and generally describe juvenile and understory forests reaching the stem exclusion phase

68 of stand development, indicating recovery from disturbance is underway. In addition, Dale et al.

69 (1991) generated paired Leslie matrix models for both Fraser fir and BWA to perform scenario

70 analysis at different elevations. This study concluded that oscillations in BWA and fir

71 populations with a cyclical pattern of mortality and recovery were likely but did not detail the

72 length of this cycle. Additionally, because temperature ranges and amplitude affected the

73 survival and fecundity of BWA, these factors had an indirect, but significant impact on future

74 Fraser fir populations. Finally, some predictive climate envelope modeling has also been

75 performed on Fraser fir based on current species distributions (Potter et al. 2010) and suggests

76 suitable habitat will shrink by 2050 and then expand again by the end of the century. However,

77 there are no predictive population models using the inventory data collected from monitoring

78 efforts. By locating specific populations that are in decline, predictive population models could

79 benefit management and conservation of this endemic species by allowing managers to

80 concentrate their efforts on these key populations.

81 In this paper, we describe past and current Fraser fir forest structure on five peaks in

82 Great Smoky Mountains National Park. Additionally, we present the first predictive population

83 models for Fraser fir in the Park: a set of stage-structured matrix models fit using Bayesian

84 methods. We then use these models to generate predictions of Fraser fir stand density in ten year

85 increments until 2050, as well as confidence estimates around those predictions.

86 2. Methods

87 2.1 Study Area

88 Fir populations were monitored by the National Park Service in five high-elevation

89 mountaintop sites in Great Smoky Mountains National Park (GSMNP). These five mountains

90 encompass nearly the entire Fraser fir range in GSMNP: Mount Sterling, Mount Guyot, Mount

91 LeConte, Mount Collins and Clingmans Dome (Figure 1). Thirty-seven long-term monitoring

92 plots were established at these sites in 1990 with roughly eight plots on each mountain 
93 (exceptions being six plots on Mount Sterling and seven on Mount Guyot). Plots measure $400 \mathrm{~m}^{2}$ 94 and are situated at different aspects and elevations, ranging from 1,722 $\mathrm{m}$ on Mount Sterling to $951,999 \mathrm{~m}$ on Mount LeConte.

962.2 Data

97 Forest plots were measured over the summers of 1990 and 2000 by National Park Service 98 (NPS) staff, and 2010 by D. Kaylor and NPS staff. Species and diameter at breast height (dbh) 99 were recorded for all adult trees $(\mathrm{dbh}>5 \mathrm{~cm})$ in each plot, which were also tagged. Total counts 100 by species of seedlings (height $<1.37 \mathrm{~m}$ ) and saplings (height $>1.37 \mathrm{~m}, \mathrm{dbh}<5 \mathrm{~cm}$ ) were also 101 recorded within twelve $1 \times 1 \mathrm{~m}$ subplots and twelve $2 \times 2 \mathrm{~m}$ subplots, respectively.

$102 \quad 2.3$ Past and Current Population Size Distributions

103 Data collected in 1990, 2000, and 2010 were used to generate both current live fir basal 104 area as well as past and current size class distributions. The dbh for all seedlings was 105 approximated as $0.5 \mathrm{~cm}$ (from an estimated range of $0-1 \mathrm{~cm}$ ); similarly, the dbh for all saplings 106 was set to $3.0 \mathrm{~cm}$ (estimated range of $1-5 \mathrm{~cm}$ ). A kernel density estimator was applied to adult 107 size data to estimate counts of adult trees in $1 \mathrm{~cm}$ increments. Error was estimated by means of a 108 leave-one-out (jackknife) cross-validation over the plots for each mountain. Because seedlings 109 are substantially more dense within plots than large overstory trees, data are reported on a log 110 scale.

\subsection{Population Model}

112 Population growth of Fraser fir on each mountaintop was modeled by a stage-structured 113 matrix with transition parameters estimated using hierarchical Bayesian inference (Figure 2).

114 The fir population is divided into four stage classes: seedlings (S), saplings/juveniles (J), non115 reproductive adults $(\mathrm{A})$, reproductive adults $(\mathrm{R})$ defined as adult trees with $\mathrm{dbh}>15 \mathrm{~cm}$, plus 116 an additional 'stage' for dead stems (D) to account for the fate of all individuals over the study 117 period. Over the two ten-year periods, individuals transitioned between stages. In the case of 118 adult trees, these individual transitions were documented; in the case of saplings and juveniles, 119 these transitions must be inferred from the aggregate count data. These stages, transitions, and 120 recruitment rates define a matrix population model (Caswell 2001; Ellner \& Guckenheimer 121 2006).

122 In the case when all transitions and recruitment events are recorded, those rates can be 123 straightforwardly estimated from observed proportions. However, when only counts are 124 available, those rates are not fully determined and the same data can be observed from different 
125 vital rates (Caswell 2001; Wood 1994). When given multiple observations with the goal of

126 determining vital rates over all samples, multiple regression techniques (Lee et al. 1977;

127 Lefkovitch 1965) and iterative methods (Lawless \& McLeish 1984; MacRae 1977) are well

128 established. However, these techniques provide point-estimates only, and combining different

129 types of data into the same model is challenging. A Bayesian approach can estimate model

130 parameters using all of the available data. Additionally, it can provide uncertainty estimates

131 around those parameters that can be propagated to functions of those parameters, such as

132 future population estimates (Gross et al. 2002).

133 Given that individuals may transition from stage to stage between observations, let $m_{i j}$

134 represent the number of individuals that were in stage $j$ at the beginning of a ten-year period

135 and were then in stage $i$ at the end of that period, including the cases where those individuals

136 remain in the same stage (i.e. $i=j$ ). These values are multinomially distributed (Welton \& Ades

137 2005) with parameters equal to the conditional probability of an individual ending in stage $i$

138 given it started in stage $j$ :

$\left.139 \quad m_{S j}, m_{J j}, m_{A j}, m_{R j}, m_{D j}\right] \sim \operatorname{Multinomial}\left(p_{S j}, p_{J j}, p_{A j}, p_{R j}, p_{D j}\right)$

140 It is these probabilities, $p_{i j}$, that define the matrix model. They are themselves given an

141 uninformative prior distribution:

$142\left[p_{S j}, p_{J j}, p_{A j}, p_{R j}, p_{D j}\right] \sim \operatorname{Dirichlet}(1,1,1,1,1)$

143 The Dirichlet is the conjugate prior to the multinomial, and ensures that:

$144 \quad p_{i j} \in[0,1]$

$145 \quad \sum_{i} p_{i j}=1$

146 These probabilities are combined with (unknown) reproductive rates, $b_{i j}$, into a matrix, G,

147 that defines a linear model of population growth:

148

$$
\mathbf{G}=\left[\begin{array}{ccccc}
p_{S S} & 0 & 0 & b_{S R} & 0 \\
p_{J S} & p_{J J} & 0 & b_{J R} & 0 \\
p_{A S} & p_{A J} & p_{A A} & 0 & 0 \\
0 & p_{R J} & p_{R A} & p_{R R} & 0 \\
p_{D S} & p_{D J} & p_{D A} & p_{D R} & 1
\end{array}\right]
$$

149 The 'dead' stage is absorbing; individuals cannot transition into a different stage after dying.

150 Reproductive adults can generate new seedlings and juveniles at rates equal to $b_{S R}$ and $b_{J R}$,

151 respectively. These reproductive rates must be non-negative but are not constrained in

152 magnitude. Finally, some theoretically possible transitions in the model that are ecologically 
153 infeasible, such as seedlings growing into reproductive adults in ten years, are defined to be 154 zero.

155 Multiplying $\mathbf{G}$ with a vector representing the number of individuals in a population within each stage at a given time, $\mathrm{v}_{t}$ generates an estimate of the stage structure at the end of a ten-year period, $\mathbf{v}_{t+1}$ :

$$
\mathbf{v}_{t+1}=\mathbf{G} \mathbf{v}_{t}+\epsilon
$$

159 where $\epsilon$ is a vector of normally-distributed errors such that:

$$
\epsilon_{i} \sim \mathrm{N}\left(0, \tau_{i}\right)
$$

$$
\tau_{i} \sim \operatorname{Gamma}(1,0.1)
$$

162 and where $\tau_{i}$ is a precision for stage $i$, each of which is given a minimally informative prior 163 distribution.

164 Because individual adult trees were tracked through time, the number of individuals that 165 remain within the non-reproductive adult class $\left(m_{A A}\right)$, remain within the reproductive class $166\left(m_{R R}\right)$, transition to reproductive adults from the non-reproductive class $\left(m_{R A}\right)$, or transition 167 from either adult stage to the dead stage $\left(m_{D A}, m_{D R}\right)$ are known for each plot. Therefore, the 168 distribution of the associated transition probabilities can be estimated directly from the 169 multinomial distribution. However, distributions for reproductive rates and the transition 170 proportions for seedlings and juveniles must be estimated indirectly from the linear model 171 using the aggregate count data. The use of the Bayesian modeling approach allows these data 172 types to be seamlessly combined to estimate distributions of all probabilities simultaneously.

173 The total number of individuals in each stage in 1990, 2000, and 2010 were tallied for each 174 plot, as were the number of known transitions. Plots on the same mountain were considered 175 together to estimate shared parameters. Bayesian hierarchical modeling was used to sample 176 from those parameter distributions using the Metropolis-Hastings algorithm (Hastings 1970) as 177 implemented in OpenBUGS (Lunn et al. 2009). The algorithm was allowed to run for 100,000 178 burn-in iterations in order to converge; samples were taken over 20,000 additional iterations.

179 Convergence was confirmed by scale reduction factors $(\hat{R})$ very near $1(|\hat{R}-1|<0.01)$ for each 180 monitored parameter (Gelman \& Rubin 1992). For each of the five sets of parameter 181 distributions sampled, five parallel chains with initial conditions selected from over-dispersed 182 distributions were aggregated for a total of 100,000 post-convergence samples. The OpenBUGS 183 model specification is available as an Appendix. 
Transition matrices of the same form as $\mathbf{G}$ were constructed from each of the 100,000 parameter samples drawn by OpenBUGS for each of the five mountains. Using each of these matrices, estimates of population structure were projected in 10-year increments from the observed stage-structured population totals on each mountain in 1990, 2000, and 2010. This provided likelihood distributions of population structure for each decade until 2050. In addition, by forecasting populations in 1990 and 2000 and comparing them to known counts in 2000 and 2010, the validity of the model was visually evaluated.

\section{3. Results}

\subsection{Past and Current Stand Structure}

Stands at Clingmans Dome, Mount LeConte and Mount Collins all showed recovery or increases in overstory fir over the last twenty years. At the time of the most recent measurements, these stands had the same average density of overstory fir-approximately 2,000 stems per hectare (Table 1). In terms of live fir basal area, average basal area was highest on Mount LeConte at $27.3\left(\mathrm{~m}^{2} \cdot \mathrm{ha}^{-1}\right)$ (Table 1).

Fraser fir stands on Clingmans Dome showed the most consistency over the last two decades of any of the five peaks sampled (Figure 3$)$. Reproductive adults $(>15 \mathrm{~cm} \mathrm{dbh})$ persisted over the last two decades, and in 2010 the forest structure had a fairly even mix of sizes with a 201 number of larger reproductive trees. Consistently high numbers of seedlings were present in all 202 three sampling times. The large number of 5-10 cm dbh trees sampled in 2000 declined by an 203 order of magnitude by 2010, but likely is the result of these trees growing and moving to larger

204 size classes, which is evidenced by an overall increase in the average number of stems per 205 hectare in mature stems between these two years (Figure 4).

206 Forest stands on LeConte, Collins and Guyot showed ongoing tree mortality, but also 207 recovery of overstory Fraser fir (Figure 3). On Mount LeConte a marked decline in seedling 208 density occurred between 1990 and 2000. While there a decline in average density of trees 8-15

$209 \mathrm{~cm}$ dbh (shown in the middle portion of the histogram in Figure 3), this is coupled with an 210 increase in trees of the largest size classes. On Mount Collins, mortality of overstory trees larger

211 than $20 \mathrm{~cm}$ dbh occurred between 1990 and 2000. This is followed by dramatic recovery, as

212 overstory fir ( $>5 \mathrm{~cm} \mathrm{dbh})$ more than doubled in the last decade (Figure 4), though large trees $>30$

$213 \mathrm{~cm}$ dbh are not currently common as at many of the other sites. On Mount Guyot, the density of 214 overstory trees $<20 \mathrm{~cm}$ dbh doubled between 1990 and 2000, however, many of the largest trees 
215 on this peak died over the last decade. This trade-off means that the average density of overstory

216 fir has remained relatively constant since 1990 at about 1,000 trees per hectare.

217 At Mount Sterling sites over the last two decades, we see a decline in seedlings and

218 saplings by an order of magnitude. Though recruitment from the understory nearly doubled the

219 average overstory fir density from 1990 to 2000, this site had the least dense coverage of

220 overstory fir at about 500 trees per hectare. Our data also showed very little increase in larger,

221 reproductive adults $(>15 \mathrm{~cm} \mathrm{dbh})$ over the monitoring period.

\subsection{Population Model}

223

Though data from all size classes were used to generate the population model, results for

224 overstory and understory size classes are presented separately for ease of interpretation. As

225 expected for a valid model, the majority of observed data points are within the 95\% prediction

226 intervals generated by the model.

227 While stands on Clingmans Dome already show the most complexity as far as live fir size

228 distributions, our population model predicts a further increase in average overstory tree density

229 by 2020. Current live standing overstory Fraser fir density is approximately 2,000 trees per

230 hectare. We predict that this will nearly double by 2020 and then level out, with densities at least

231 as equal to current levels by 2050 (Figure 4). For understory size classes, we predict live fir

232 density will stay relatively constant with a slight increase over time indicating continued

233 reproduction (Figure 5).

234 By contrast, model results for Mount LeConte predict that overstory Fraser fir densities

235 will stay at a relatively consistent level at about 2,500 adult trees per hectare (Figure 4). For

236 understory stems, this level will decline by 2020, likely due to stem exclusion of smaller trees.

237 However, as on Clingmans Dome, we predict a slight increase over time indicating continued

238 Fraser fir reproduction (Figure 5).

239 Though stands on Mount Collins increased in overstory fir dramatically over the last

240 decade, this average density is predicted to decline in the next twenty years. By 2040, the

241 predicted average live overstory Fraser fir densities will reach that suggested by applying the

242 model to the 1990 data (Figure 4). Understory fir by contrast is expected to remain fairly

243 constant through mid-century (Figure 5).

244 On Mount Guyot, which has had a relatively constant density of adult trees in the

245 overstory at around 1,000 trees per hectare, our model predicts an increase by another 500 
246 overstory trees per hectare by 2020. This increase will be followed by a slow decline, with levels

247 returning to what they were in 1990 by 2050 (Figure 4). Understory stems also will continue to 248 decline (Figure 5).

249 Lastly, for Fraser fir populations on Mount Sterling, our model predicts no increase in 250 overstory fir densities, but a steady decline reaching below 1990 levels by 2050 (Figure 4). We

251 predict a steady average density of understory stems at around 250 individuals per hectare

252 (Figure 5).

253 4. Discussion

Pre-adelgid forest census data collected in GSMNP in the 1930's suggest that Fraser fir

255 forests were fairly uniform across peaks within the park with an estimated average Fraser fir 256 basal area of $40.7 \mathrm{~m}^{2} \cdot \mathrm{ha}^{-1}$ and an average total basal area of $55.9 \mathrm{~m}^{2} \cdot \mathrm{ha}^{-1}$ (Busing et al., 1993).

257 Average Fraser fir basal areas measured in the present study are considerably lower than these

258 estimates; average total basal area (which includes red spruce and hardwood species) is 37.9

$259 \mathrm{~m}^{2} \cdot \mathrm{ha}^{-1}$ (Franklin \& Kaylor 2014), also much lower than measured in the 1930's. Additionally,

260 stands at Clingmans Dome, Mount LeConte, and Mount Collins all show recovery or increases in

261 overstory fir density over the last twenty years. When considering this most recent inventory

262 data, there is no evidence to support the elimination of Fraser fir as suggested by Smith (1995)

263 and Smith and Nicholas (1998), based on earlier inventories. In addition to recovery in Great

264 Smoky Mountains National Park detailed in this study, Fraser fir forest recovery is also

265 underway on Roan Mountain (White et al. 2012), and in the Black Mountains (Lusk et al. 2010;

266 McManamay et al. 2011).

267 While overstory forest inventory data are often used to monitor forest recovery, seedling

268 production and the transition rates between life stages are essential components in predicting

269 future forest dynamics. The dramatic declines in seedling density, which are most extreme on

270 Mount LeConte and Mount Sterling over the two decades of monitoring (Figure 3), have been

271 previously noted (Mancusi 2004; Smith \& Nicholas 2000; Smith 1995). These declines in

272 seedlings may have been caused by increased forest floor insolation (Smith \& Nicholas 2000),

273 understory competition (Mancusi 2004; Smith \& Nicholas 2000; Smith 1995), or lowered seed

274 production or viability (Fedde 1973; Nicholas 1992). It is only by considering seedling

275 abundance within the context of longer-term population dynamics that this data set becomes

276 useful in predicting the restoration and maintenance of a viable fir overstory (Clark et al. 1999). 
277 Our models are dynamic over multiple life stages and account for misperceptions that can arise

278 when focusing on a single life stage or transition. While many individual plots show large

279 reductions in seedling densities over the last two decades, we predict relatively stable overstory

280 fir populations and continued reproduction on Mount LeConte and Clingmans Dome. As has

281 been noted in earlier surveys in Great Smoky Mountains National Park (Stehn et al. 2013;

282 Jenkins 2003; Smith \& Nicholas 2000), Fraser fir regeneration is patchy and has been linked to

283 disturbance history, elevation, and soil nutrient content (Stehn et al. 2013); this patchiness is

284 exhibited in the uncertainty estimates in our model.

285 However, our model does predict a steady decline in the Fraser fir population on Mount

286 Sterling, the lowest elevation mountain in our study. These predictions are consistent with

287 previous estimates of future suitable habitat for Fraser fir using a multi-temporal spatial

288 clustering method of climate envelope modeling (Potter et al. 2010), which showed a pattern of

289 suitable habitat contraction by 2050 and slight expansion by 2100 . Additionally, Delcourt and

290 Delcourt (1998) hypothesize that a $3^{\circ} \mathrm{C}$ increase in mean July temperatures will raise the lower

291 bound of Fraser fir's habitat $480 \mathrm{~m}$ in elevation by $2100 \mathrm{CE}$. The continued decline of Fraser fir

292 on Mount Sterling may be evidence of habitat suitability shifts caused by long-term

293 environmental changes. Additionally it may also indicate that differences in annual temperature

294 range and amplitude at lower elevations benefit insect survival and dispersal as suggested by

295 Dale et al. 1991.

296 The method we present here differs widely from other approaches like niche modeling,

297 which uses current presence-absence data of a species and current and future environmental site

298 parameters to predict the future extent of the species of interest (Godsoe 2010; Elith \&

299 Leathwick 2009; Peterson 2003). These models are biased by historical land use change which

300 limits the current geographic coverage of species. Further, the spatial resolution of predictions

301 generated by niche models is limited by the spatial resolution of available environmental data.

302 Additionally, they are not able to incorporate past population dynamics or generate predictions of

303 differing densities, which is a strength of the approach we have used.

304 The predictive population model we present here assumes no changes will occur in

305 current and chronic stress factors. Because the population data and transition rates on each

306 mountain incorporate individual tree response to multiple environmental parameters (acidic

307 deposition, climate, BWA induced mortality, and others), these are implied in the model and are 
308 a source of variability/uncertainty. If, however, these factors change in the future, then our model

309 cannot anticipate or account for the effects this would have on future population dynamics.

310 Further, the model assumes that the population will not change in its response to ongoing

311 stresses. However, the gene pool may undergo future changes due to selective pressure and/or

312 limited and isolated populations.

313 Although matrix-models similar to the one presented in this study often rely on

314 eigenvalue analysis to determine the eventual fate of the population (Caswell 2001; Ellner \&

315 Guckenheimer 2006), the long-term dynamics of the Fraser fir forests in the Smoky Mountains

316 are complex and deeply uncertain. Simple linear models such as the one constructed here cannot

317 generate reliable predictions centuries into the future. Therefore our analysis focuses on the

318 relatively short-term transient dynamics of these populations that is enabled by using the

319 distribution-generating tools of Bayesian methods.

320 The comparison of model predictions of populations in 1990 and 2000 and known counts

321 in 2000 and 2010 provides a visual estimate of model validity. Overall, our model accurately

322 predicts observed data within a 95\% prediction interval of the models applied to the 1990 data,

323 with notable exceptions being the 2010 overstory fir density for Mount Collins (Figure 4) and the

3242000 understory density on Mount Sterling. For Mount Collins, this is likely due to the ongoing

325 overstory mortality between 1990 and 2000 and release of smaller size classes into the overstory

326 (Figure 3). Alternatively, it may be that fir populations at Mount Collins are too unstable to

327 model using our approach, or that there are differing population trajectories occurring in different

328 plots across this site. However, when 95\% prediction intervals are applied to the 2000 data, we

329 clearly see that observed data are on the upper bound of our predicted intervals for both 2000 and

330 2010. For the Mount Sterling understory, this unexpected spike in the seedling and sapling size

331 class is caused by seedling increases in a single plot. Such spikes in seedling densities are not

332 uncommon following canopy removal, but are often followed by self-thinning as our data

333 demonstrate. Additionally, observed seedling densities at Mount Sterling are currently within

334 the $95 \%$ prediction intervals so we believe our model predictions to be accurate.

335 Two important factors influencing the future of Fraser fir are the severity and timing of

336 future BWA-induced mortality. Frequent and severe mortality events would cause a dramatic

337 departure of this forest type from pre-BWA conditions, while infrequent or milder-mortality

338 events may yield a forest that is quite similar to pre-BWA forests with stable populations of 
339 Fraser fir. The emergence of a two aged forest with cyclical BWA outbreaks and overstory fir 340 mortality followed by a regeneration period has been hypothesized (Dale et al. 1991; Eagar 341 1984; Mancusi 2004; Smith \& Nicholas 1998, 2000). We do not yet see evidence of this pattern

342 in these long-term monitoring plots across mountains, which suggests a patchy forest structure 343 that has also been noted in the Black Mountains (McManamay et al. 2011). Forests on Mount

344 Sterling experienced widespread fir death at the summit in 1970-1972, on Mount Guyot in 345 1980-1982, Mount LeConte in 1982-1984, Mount Collins in 1985-1987, and Clingmans Dome 346 in 1990-1992 (Smith \& Nicholas 2000). The generation time of Fraser fir is roughly 15 years

347 from seedling to the onset of reproductive maturity (Beck 1990) and even the most recently 348 infested site surpasses this period. Trees greater than $4 \mathrm{~cm}$ dbh are susceptible to BWA-induced 349 mortality (Eager 1984), which is sooner than the onset of reproduction. While the exact timing of future mortality events is unknown, forest structural

351 complexity may provide some resilience to large infrequent disturbances. Stands where a number

352 of large trees persisted through the infestation, like those on Clingmans Dome, may recover more 353 quickly due to the presence of reproductive trees. Other stands with very little overstory

354 persistence are limited by the survival and maturation of trees present in the understory at initial 355 disturbance. This creates a mosaic-like structure of stands in different stages of regeneration, 356 which has been previously noted (Jenkins, 2003; Smith \& Nicholas, 2000; McManamay et al.

357 2011). Because BWA feeds on mature fir and a contiguous, dense overstory of large, mature fir 358 no longer exists, this structural complexity may provide some resilience to future BWA 359 mortality.

360 When comparing projected future populations between mountains, clear differences 361 between them emerge. While proximal causes for these differences in outcomes are likely the 362 aforementioned differences in forest structure, there are a number of possible reasons for the 363 persistence of mature trees and the differences in regeneration and mortality rates at different 364 sites. Genetic differences between populations in response to environmental stresses are likely.

365 Individual trees can show a tremendous ability to acclimate to a changing environment, with the 366 magnitude and variability of this response dependent upon species (Tjoelker et al. 1999), 367 provenance (Bigras 2000), elevation (Ledig \& Fryer 1972), and other factors. In a study of red 368 spruce (a species co-dominant with Fraser fir) acclimation and adaptation to elevated 369 temperatures (Hagen 2006), seedlings grown from seeds collected at one of four sites in the 
370 GSMNP showed a significantly different response to an increase in growth temperature,

371 suggesting that individuals capable of thriving under predicted temperatures may exist within

372 local populations. The longevity, vigor, and fecundity of trees are determined, at least in some

373 part, by tree physiological parameters like photosynthetic rates, water use efficiency, and the size

374 of nonstructural carbohydrate pools which likely differ between trees in different locations. In

375 addition, environmental factors like temperature, precipitation, and soil chemistry differ across

376 elevations and aspects. Additionally, recent work has highlighted the importance of cloud water

377 and cloud immersion on Fraser fir physiology (Berry \& Smith 2013; Reinhardt \& Smith 2008). It

378 is possible that cloud immersion differs across the study area and may account for some of the

379 variation between predicted populations. It is clear that an understanding of the important

380 environmental factors that affect individual tree physiology is needed before long-term

381 predictions of population dynamics can be made.

\section{5. Conclusions}

383 We present the first predictive model for Fraser fir populations in Great Smoky

384 Mountains National park. We predict robust recovery of select Fraser fir populations for at least

385 the next several decades, as well as continued decline for populations on a number of mountains,

386 notably those at the lowest elevations. Our data suggest forest structural complexity may provide

387 some resilience to large infrequent disturbances like BWA infestation. Stands where a number of

388 large trees persisted through the infestation may recover more quickly due to the presence of

389 reproductive trees. This suggests management strategies that protect a selection of robust and

390 reproductively mature individuals will improve recovery of Fraser fir populations through further

391 mortality events. Further, our findings highlight vulnerable populations which would benefit

392 from limiting human impacts on successful reproduction and recruitment, and may also be

393 appropriate sites for Fraser fir plantings.

\section{Acknowledgements}

396 The authors would like to thank NPS Great Smoky Mountains National Park for providing the 3971990 and 2000 datasets, funding, and field crews, and Josh Albritton and Blaise Moehl for data 398 collection assistance. Thanks are also extended to Dr. Tim Young, Dr. Jenn Schweitzer, and Dr.

399 Joe Bailey for their comments and insight, as well as the three reviewers for their suggestions. 


\section{References}

Beck D. 1990. Abies fraseri. In: Burns RM, Honkala BH, editors. Silvics of North America, Vol. 1: Conifers. U.S. Department of Agriculture, Forest Service, Washington, D.C. p. 47-51.

Berry ZC, Smith WK. 2013. Ecophysiological importance of cloud immersion in a relic sprucefir forest at elevational limits, southern Appalachian Mountains, USA. Oecologia 173(3):637-48.

Bigras FJ. 2000. Selection of white spruce families in the context of climate change: heat tolerance. Tree Physiology 20:1227-1234.

Borer CH, Schaberg PG, DeHayes DH. 2005. Acidic mist reduces foliar membrane-associated calcium and impairs stomatal responsiveness in red spruce. Tree Physiology 25:673-680.

Busing RT, Clebsch EEC, Eagar CC, Pauley EF. 1988. Two Decades of Change in a Great Smoky Mountains Spruce-Fir Forest. Bulletin of the Torrey Botanical Club 115:25-31.

Busing RT, White PS, MacKenzie MD. 1993. Gradient analysis of old spruce-fir forests of the Great Smoky Mountains circa 1935. Canadian Journal of Botany 71:951-958.

Caswell H. 2001. Matrix Population Models: Construction, Analysis, and Interpretation. $2^{\text {nd }}$ Ed. Sunderland (MA): Sinauer Associates.

Christensen NL, Bartuska AM, Brown JH, Carpenter S, D’Antonio C, Francis R, Franklin JF, MacMahon JA, Noss RF, Pasrons DJ, et al. 1996. The Report of the Ecological Society of America Committee on the Scientific Basis for Ecosystem Management. Ecological Applications 6:665-691.

Clark JS, Beckage B, Camill P, Cleveland B, Hillerislambers J, Lichter J, McLachlan J, Mohan J, Wyckoff P. 1999. Interpreting Recruitment Limitation in Forests. American Journal of Botany 86:1-16.

Dale VH, Gardner, RH, DeAngelis DL, Eagar CC, Webb JW. 1991. Elevation-mediated effects of balsam woolly adelgid on southern Appalachian spruce-fir forests. Canadian Journal of Forest Research 21:1639-1648.

Delcourt PA, Delcourt HR. 1998. Paleoecological Insights on Conservation of Biodiversity: A Focus on Species, Ecosystems and Landscapes. Ecological Applications 8:921-934. 
Dull CW, Ward JD, Brown HD, Ryan GW, Clerke WH, Uhler RJ. 1988. Evaluation of spruce and fir mortality in the southern Appalachian Mountains. USDA Forest Service Southern Region R8-PR 13, Atlanta, GA.

Eager C. 1984. Review of the biology and ecology of the balsam woolly aphid in Southern Appalachian spruce-fir forests. In: White PS, editor. 1984. The southern Appalachian spruce-fir ecosystem: its biology and threats. USDI National Park Service, Southeast Region, Research/Resources Management Report SER-71, Atlanta, GA.

Elith J, Leathwick JR. 2009. Species distribution models: ecological explanation and prediction across space and time. Annual Review of Ecology, Evolution, and Systematics 40:677697.

Ellner SP, Guckenheimer J. 2006. Dynamic Models in Biology. Princeton (NJ): Princeton University Press.

Fedde GF. 1973. Impact of the balsam woolly aphid on cones and seed produced by infested Fraser fir. Canadian Entomologist 105:673-680.

Franklin JA, Kaylor SD. 2014. Evaluate Changes in Spruce- Fir Forests to Identify Impacts of Exotic Insect and Climate Change. Report for the Southern Appalachian Cooperative Ecosystems Studies Unit (CESU). US Department of the Interior, National Park Service, Gatlinburg, TN.

Gelman A, Rubin DB. 1992. Inference from Iterative Simulation Using Multiple Sequences. Statistical Science 7:457-472.

Godsoe W. 2010. I can't define the niche but I know it when I see it: a formal link between statistical theory and the ecological niche. Oikos 119: 53-60.

Gross K, Craig BA, Hutchison WD. 2002. Bayesian Estimation of a Demographic Matrix Model from Stage-Frequency Data. Ecology 83:3285-3298.

Hagen JW. 2006. Physiologic Acclimation of Southern Appalachian Red Spruce to Simulated Climatic Warming [thesis]. [Knoxville (TN)]: University Of Tennessee Knoxville.

Hastings WK. 1970. Monte Carlo sampling methods using Markov chains and their applications. Biometrica 57:97-109.

Hollingsworth RG, Hain FP. 1991. Balsam Woolly Adelgid (Homoptera: Adelgidae) and Spruce-Fir Decline in the Southern Appalachians: Assessing Pest Relevance in a 
Damaged Ecosystem. Florida Entomologist 74:179-187.

Jacobson JS, Heller LI, Yamada KE, Osmeloski JF, Bethard T, Lassoie JP. 1990. Foliar injury and growth response of red spruce to sulfate and nitrate acidic mist. Canadian Journal of Forest Research 20:58-65.

Jenkins MA. 2003. Impact of the Balsam Woolly Adelgid (Adelges piceae Ratz.) on an Abies fraseri ( Pursh ) Poir . Dominated Stand Near the Summit of Mount LeConte, Tennessee. Castanea 68:109-118.

Lawless JF, McLeish DL. 1984. The Information in Aggregate Data from Markov Chains. Biometrika 71:419-430.

Ledig FT, Fryer JH. 1972. A pocket of variability in Pinus rigida. Evolution 26:259-266.

Lee TC, Judge GG, Zellner A. 1977. Estimating the Parameter of the Markov Probability Model from Aggregate Time Series Data, $2^{\text {nd }}$ Rev. Amsterdam and London: North-Holland.

Lefkovitch LP. 1965. The Study of Population Growth in Organisms Grouped by Stages. Biometrics 21:1-18.

Lunn D, Spiegelhalter D, Thomas A, Best N. 2009. The BUGS project: Evolution, critique and future directions. Statistics in Medicine 28:3049-3067.

Lusk L, Mutel M, Walker E, Levy F. 2010. Forest change in high-elevation forests of Mt. Mitchell, North Carolina: re-census and analysis of data collected over 40 years. In: Rentch J, Heitzman E, editors. Snowshoe, West Virginia, May 14-15, 2009. General Technical Report NRS. United States Department of Agriculture, Forest Service, Northern Research Station. Morgantown, West Virginia. p. 104-112.

MacRae EC. 1977. Estimation of Time-Varying Markov Processes With Aggregate Data. Econometrica 45:183-198.

Mancusi MR. 2004. Structural changes in the red spruce-Fraser fir forest [thesis]. [Knoxville (TN)]: University of Tennessee Knoxville.

McLaughlin SB, Anderson CP, Edwards NT, Roy WK, Layton PA. 1990. Seasonal patterns of photosynthesis and respiration of red spruce saplings from two elevations in declining southern Appalachian stands. Canadian Journal of Forest Research 20:485-495.

McManamay RH, Resler LM, Campbell JB. 2011. Assessing the impacts of balsam woolly 
adelgid (Adelges piceae Ratz.) and anthropogenic disturbance on the stand structure and mortality of Fraser fir [Abies fraseri (Pursh) Poir.] in the Black Mountains, North Carolina. Castanea 76:1-19.

Moore PT, Van Miegroet H, Nicholas NS. 2008. Examination of forest recovery scenarios in a southern Appalachian Picea-Abies forest. Forestry 81:183-194.

Nicholas NS. 1992. Stand structure, growth and mortality in Southern Appalachian Spruce-Fir [dissertation]. [Blacksburg (VA)]: Virginia Polytechnic Institute and State University.

Nodvin SC, Van Miegroet H, Lindberg SE, Nicholas NS, Johnson DW. 1995. Acidic deposition, ecosystem processes, and nitrogen saturation in a high elevation Southern Appalachian Watershed. Water, Air, \& Soil Pollution 85:1647-1652.

Oosting HJ, Billings WD. 1951. A comparison of virgin spruce-fir forest in the northern and southern Appalachian system. Ecology 32(1):84-103.

Peterson AT. 2003. Predicting the geography of species' invasions via ecological niche modeling. The Quarterly Review of Biology 78(4): 419-433.

Potter KM, Hargrove WW, Koch FH. 2010. Predicting climate change extirpation risk for central and southern Appalachian forest tree species. In: Rentch JS, Schuler TM, editors. 2010. Proceedings from the conference on the ecology and management of high-elevation forests in the central and southern Appalachian Mountains. 2009 May14-15; Slatyfork, WV. Gen. Tech. Rep. NRS-P-64. Newtown Square, PA: U.S. Department of Agriculture, Forest Service, Northern Research Station. p. 179-189.

Pyle C, Schafale MP. 1988. Land Use History of Three Spruce-Fir Forest Sites in Southern Appalachia. Journal of Forest History 32:4-21.

Reinhardt K, Smith WK. 2008. Impacts of cloud immersion on microclimate, photosynthesis and water relations of Abies fraseri (Pursh.) Poiret in a temperate mountain cloud forest. Oecologia 158:229-38.

Smith GF. 1995. Regeneration of Fraser Fir After Thirty Years of Balsam Woolly Adelgid Infestation. [thesis]. [Knoxville, (TN)]: University of Tennessee Knoxville.

Smith GF, Nicholas NS. 2000. Size- and age-class distributions of Fraser fir following balsam woolly adelgid infestation. Canadian Journal of Forest Research 30:948-957.

Smith GF, Nicholas NS. 1998. Patterns of overstory composition in the fir and fir-spruce forests 
of the Great Smoky Mountains after balsam woolly adelgid infestation. American Midland Naturalist 139:340-352.

Stehn, S. E., M. A. Jenkins, C. R. Webster, and S. Jose. 2013. Regeneration responses to exogenous disturbance gradients in southern Appalachian Picea-Abies forests. Forest Ecology and Management 289:98-105.

Tjoelker MG, Oleksyn J, Reich PB. 1999. Acclimation of respiration to temperature and CO2 in seedlings of boreal tree species in relation to plant size and relative growth rate. Global Change Biology 49:679-691.

Welton NJ, Ades AE. 2005. Estimation of Markov chain transition probabilities and rates from fully and partially observed data: uncertainty propagation, evidence synthesis, and model calibration. Medical Decision Making 25(6): 633-645.

White P, van de Gevel SL, Soulé PT. 2012. Succession and disturbance in an endangered red spruce-Fraser fir forest in the southern Appalachian Mountains, North Carolina, USA. Endangered Species Research 18:17-25.

White PS, editor. 1984. The southern Appalachian spruce-fir ecosystem: its biology and threats. USDI National Park Service, Southeast Region, Research/Resources Management Report SER-71, Atlanta, GA.

Whittaker RH. 1956. Vegetation of the Great Smoky Mountains. Ecological Monographs 26:180.

Wood SN. 1994. Obtaining Birth and Mortality Patterns from Structured Population Trajectories Ecological Monographs 64:23-44. 
Table 1: Average basal area of Fraser fir $\geq 5 \mathrm{~cm}$ dbh and overstory density (with standard errors) from 37 long-term monitoring plots on 5 peaks in Great Smoky Mountains National Park re-measured in 2010 and 2011.

\begin{tabular}{ccccc}
\hline Mountain & $\begin{array}{c}\text { Elevation Range } \\
(\mathrm{m})\end{array}$ & Number of Plots & $\begin{array}{c}\text { Fir Basal Area (SE) } \\
\left(\mathrm{m}^{2} \cdot \mathrm{ha}^{-1}\right)\end{array}$ & $\begin{array}{c}\text { Fir overstory } \\
\text { density }\left(n \cdot \mathrm{ha}^{-1}\right)\end{array}$ \\
\hline \hline Clingmans Dome & $1,937-1,993$ & 8 & $18.4(2.8)$ & $2640(530)$ \\
Mount LeConte & $1,892-1,999$ & 8 & $27.3(5.7)$ & $3200(550)$ \\
Mount Collins & $1,821-1,887$ & 8 & $15.7(2.9)$ & $2750(750)$ \\
Mount Guyot & $1,913-1,990$ & 7 & $13.7(5.3)$ & $2440(700)$ \\
Mount Sterling & $1,722-1,783$ & 6 & $7.5(2.1)$ & $800(180)$ \\
\hline
\end{tabular}




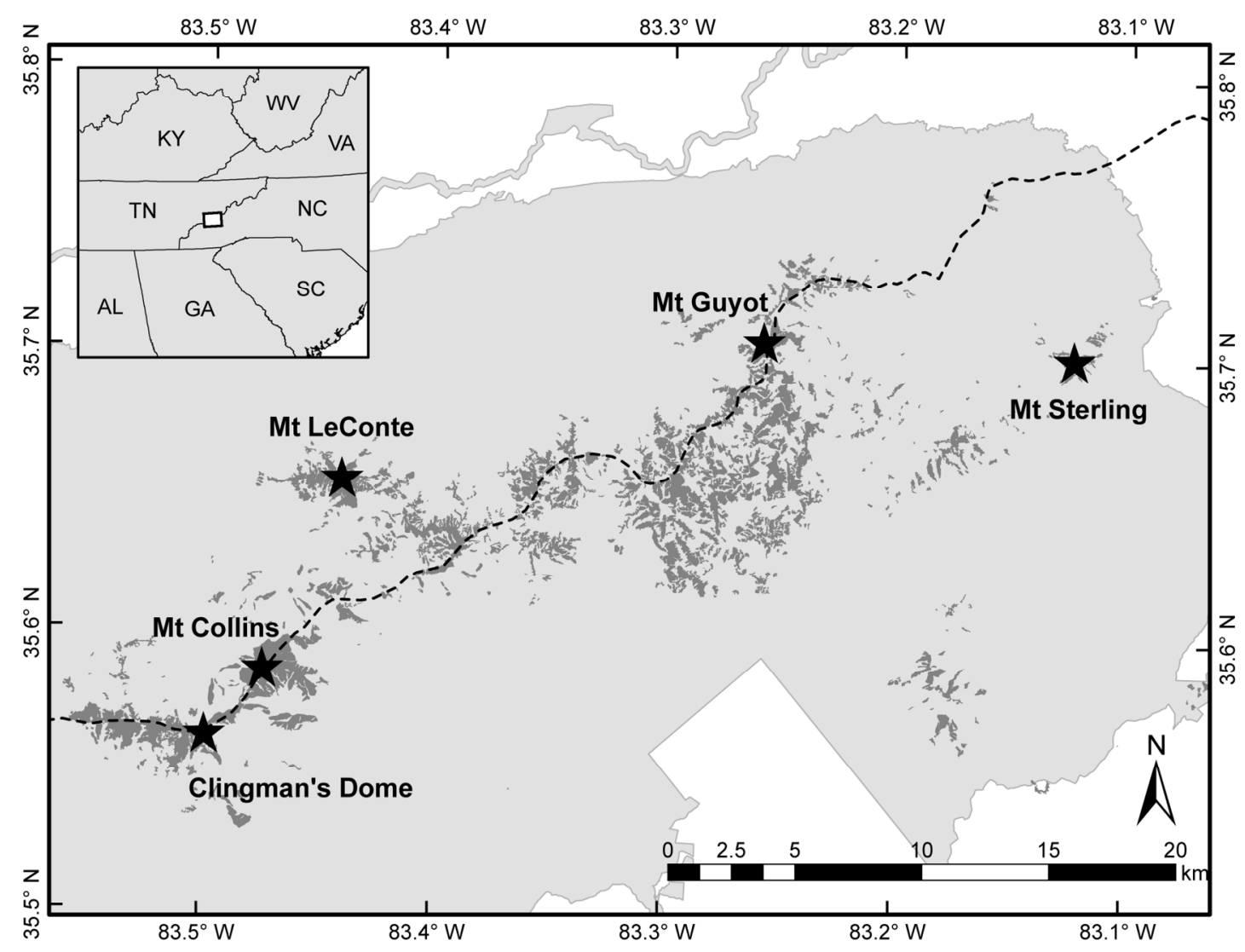

Figure 1: Map of study area within Great Smoky Mountains National Park. Light grey shading denotes park boundary. Dark grey shading represents red spruce-Fraser fir forest cover provided as a GIS layer from the National Park Service. Stars denote the five mountains where monitoring plots are located. 


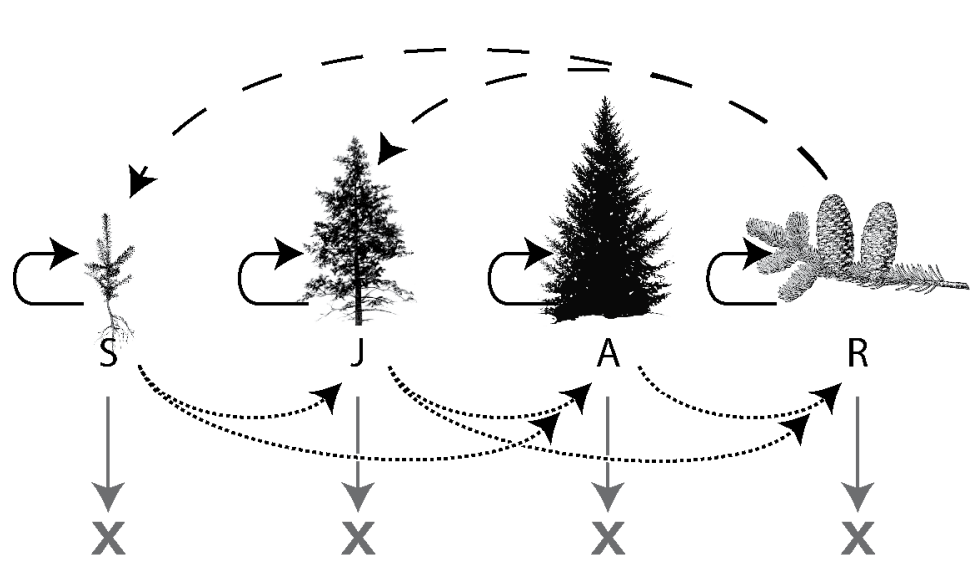

402

Figure 2. Model schematic showing stages for seedlings (S), saplings (juveniles, J), nonreproductive adults $(\mathrm{A})$, and reproductive adults $(\mathrm{R})$. Between 10-year iterations, individuals may remain in their current stage (solid black arrows), transition to an older stage (dotted arrows), or die (gray arrows); additionally, reproductive adults may generate new individuals in the seedling or, less frequently, juvenile class (dashed arrows). 


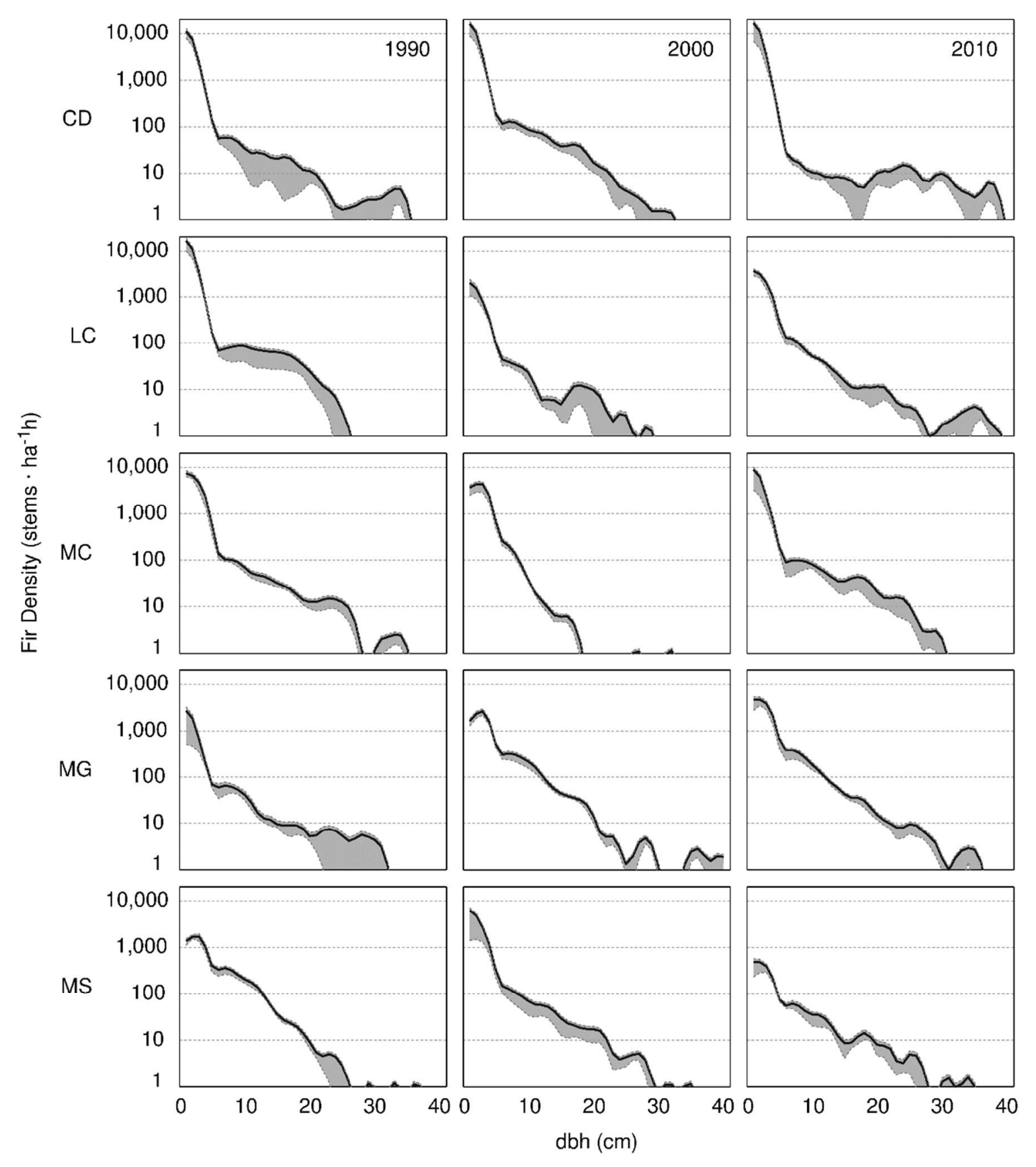

Figure 3. Size class histograms for five populations of Fraser fir in Great Smoky Mountains National Park: Clingmans Dome (CD), Mount LeConte (LC), Mount Collins (MC), Mount Guyot (MG), and Mount Sterling (MS). Charts show $1 \mathrm{~cm}$ DBH size classes in 1990 (right), 2000 (center) and 2010 (left) reported on a log scale. The gray region is the area between the minimum and maximum estimations from jack-knifed cross-validation and represents uncertainty due to sampling; the dark line is the mean for all plots. 

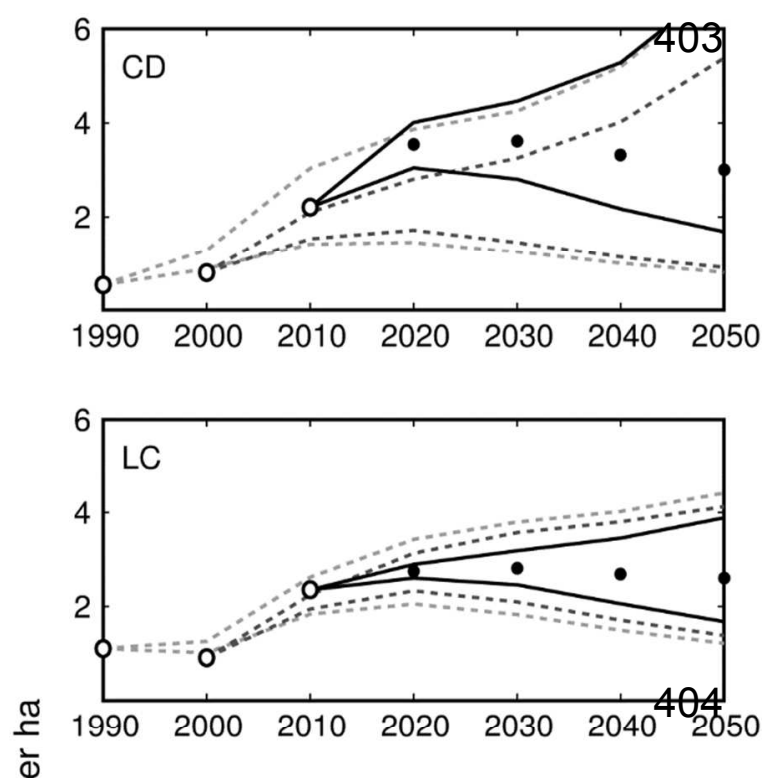

ज)
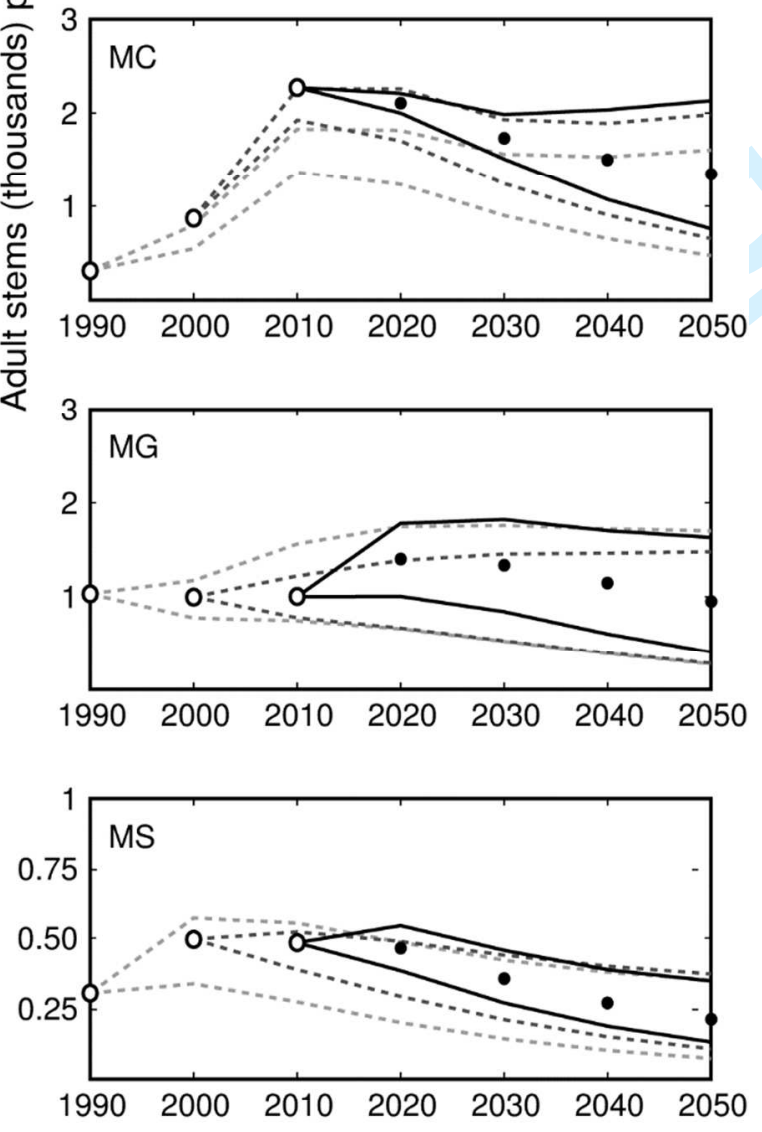

Figure 4. Bayesian population model predictions for overstory adult $(>5 \mathrm{~cm}$ dbh) Fraser fir on 5 mountains in Great Smoky Mountains: Clingmans Dome, Mt LeConte, Mt Collins, Mt Guyot and Mt Sterling (top bottom). Open circles represent measured densities, black dots are projected means. Light gray dotted lines represent the $95 \%$ prediction interval of the model as applied to the initial measurements in 1990, dark grey dotted lines are the same bounds as applied to 2000 data, and solid lines the same for $\mathbf{2 0 1 0}$ data. 

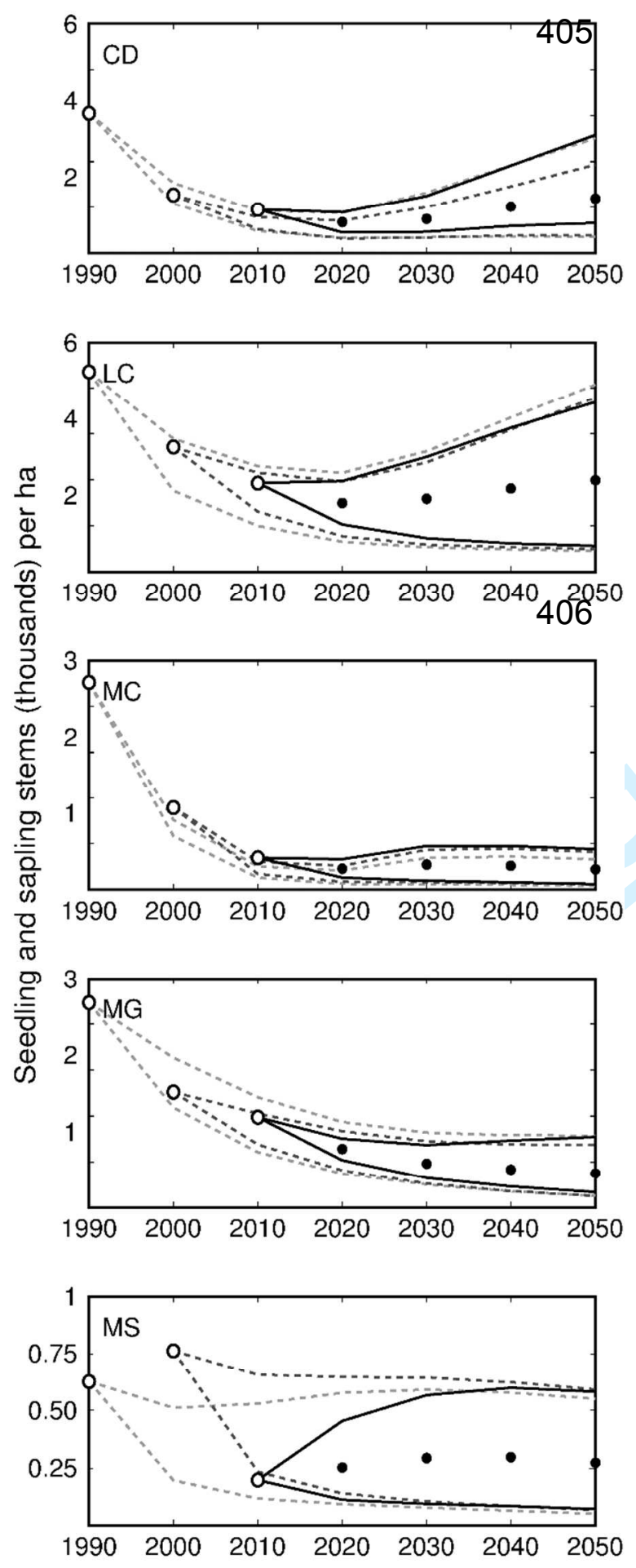

Figure 5. Bayesian population model predictions for understory seedlings and saplings ( $<5 \mathrm{~cm}$ dbh) Fraser fir on 5 mountains in Great Smoky Mountains: Clingmans Dome, Mt LeConte, Mt Collins, Mt Guyot and Mt Sterling (top - bottom). Open circles represent measured densities, black dots are projected means. Light gray dotted lines represent the $\mathbf{9 5 \%}$ prediction interval of the model as applied to the initial measurements in 1990, dark grey dotted lines are the same bounds as applied to 2000 data, and solid lines the same for 2010 data. 


\section{Appendix}

408 model \{

409

410

\# get survival and transition rates of adults from Panel Data

411

\# SUmA[i] and sumR[i] are the same as $A \theta[i]$ and $R \theta[i]$, except that

412

\# samples with $A \theta[i]==\theta$ or $R \theta[i]==0$ are removed since those are

413

\# not allowed as parameters to dmulti or dbinom

414 for ( $i$ in 1:NUM_ADULT_SAMP) \{

$415 \operatorname{sumA}[i]<-\operatorname{sum}(\operatorname{A2ARD}[i, 1: 3])$;

$416 \operatorname{A2ARD}[i, 1: 3] \sim \operatorname{dmulti}(\operatorname{Pa}[1: 3], \operatorname{sum} A[i])$

$417\}$

418

419

420

421

422

423

424

425

426

427

428

429

430

431

432

433

434

435

436

437

438

439

440

441

442

443

444

445

446

447

448

449

450

451

452

for ( $i$ in 1:NUM_REPROD_SAMP) \{

R2R[i] dbin(Prr, sumR[i]) \}

\# get other transition probabilities from aggregate data

for ( $i$ in 1:NUM_SAMPLES) \{

\# Define the transition model

S1_mu[i] <- Pss*SO[i] + Bsr*RO[i]

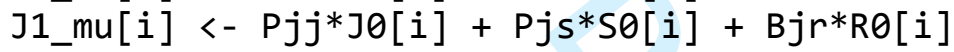

A1_mu[i] <- Paa*AO[i] + Paj*JO[i] + Pas*SO[i]

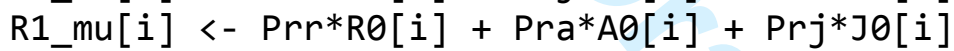

\# Same as putting a noise term on the above equations

$\mathrm{S} 1[\mathrm{i}] \sim \operatorname{dnorm}(\mathrm{S} 1$ mu[i], tau_S)

J1[i] $\sim \operatorname{dnorm}(J 1$ mu[i], tau_J)

A1[i] dnorm(A1_mu[i], tau_A)

\}

R1[i] dnorm(R1_mu[i], tau_R)

\# Uninformative prior on precision of normal distribution

tau_S dgamma $(1,0.1)$

tau_J dgamma $(1,0.1)$

tau_A dgamma $(1,0.1)$

tau_R $\sim \operatorname{dgamma}(1,0.1)$

\# Probabilties of moving from Seedlngs

Ps [1:4] ddirch(alpha4[])

Pss <- Ps[1]

Pjs $<-P s[2]$

Pas <- Ps[3]

\# Probabilties of moving from Juveniles

$\operatorname{Pj}[1: 4] \sim \operatorname{ddirch}(a l p h a 4[])$

$P j j<-P j[1]$

453 Paj <- Pj[2]

$454 \quad \operatorname{Prj}<-\operatorname{Pj}[3]$ 


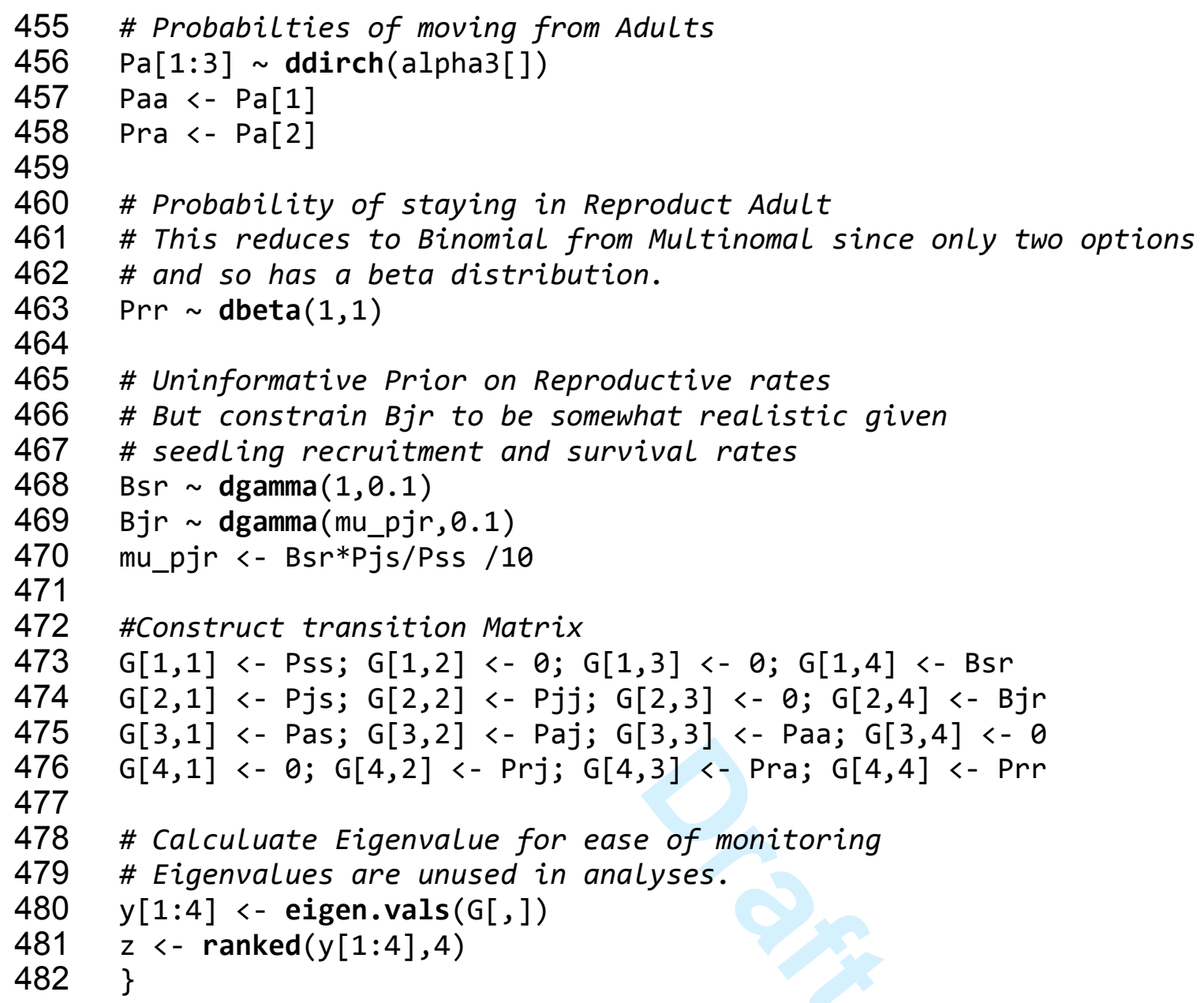

